\title{
Mass Maldistribution Research of Different Internal Flowing Channels in the Cooling Plate Applied to Electric Vehicle Batteries
}

\author{
Huikun Cai *, Chen Xu, Yidai Liao, Lijun Su and Zeju Weng \\ Department of Mechanical and Electronic Engineering of Xiamen University, Room 263 of Aerospace \\ Engineering Building, 4221-134 Xiangan South Road, Xiangan South District, Xiamen 361102, China; \\ xcqshg@hotmail.com (C.X.); m159592730561@163.com (Y.L.); 19920171281425@stu.edu.cn (L.S.); \\ 19920161151466@stu.edu.cn (Z.W.) \\ * Correspondence: caihuikun@xmu.edu.cn; Tel.: +86-156-5926-9026
}

Received: 26 December 2018; Accepted: 30 January 2019; Published: 14 February 2019

\begin{abstract}
As temperature variations will cause electrochemical reactions to proceed at different rates in different regions of the cell, which thereby leads to incomplete energy utilization and inefficient management of battery life, temperature uniformity is becoming a new challenge in thermal management systems of electric vehicle batteries. With the wide application of liquid cooling strategies, temperature uniformity is significantly affected by coolant mass maldistribution, which is significantly affected by the flowing channel configuration in the cooling plate. However, there are few papers on this influence presently. Therefore, this paper presents numerical research on cooling plates with different internal flowing channels. A comparison of the effects among three channel configurations (cavity, parallel, and serpentine) on coolant flowing characteristics is carried out by analyzing their mass maldistribution coefficients and pressure drops. Then, a serpentine channel is selected for further optimization by an orthogonal experiment and range analysis method due to its better comprehensive performance. The study aims to reveal design principles on how channel configuration acts on mass maldistribution, and to demonstrate that significant performance gains can be realized with optimization techniques that can be utilized in battery cooling plates.
\end{abstract}

Keywords: electric vehicle battery; thermal management system; mass maldistribution; flowing channel configuration; cooling plate

\section{Introduction}

The performance of an electric vehicle (EV) depends strongly on its battery pack performance. Due to its better characteristics in terms of capacity, energy densities, charge retention, life cycles, and competitive cost when compared with other rechargeable batteries, lithium-ion (Li-ion) battery technology has been considered to be one of the most promising long-term advanced battery technologies and hence is widely used in modern EVs [1]. However, the battery pack is encountering more and more thermal problems with the demands of long-drive and huge-power EVs. Presently, researchers have come to a consensus that the best range of work temperature for a Li-ion battery is $10-40{ }^{\circ} \mathrm{C}$, and once its temperature is above $50^{\circ} \mathrm{C}$, battery efficiency and life will deteriorate quickly. Especially when a battery module works at $80-119{ }^{\circ} \mathrm{C}$ but without in-time heat dissipation, solid electrolyte interfaces will dissolve, which can lead to batter over-charging and internal short circuiting, or even pose a safety hazard [2,3].

Mathematical simulation of heat transfer within large batteries is an effective tool to obtain knowledge about whether excessive heat generated during the battery charge or discharge process can be removed, and how operating temperature can be controlled. Chen et al. [4] built a two-dimensional 
model to study the effect of various cell components, stack size, and cooling conditions on the performance of Li-polymer electrolyte batteries under different discharge C-rates (C-rate means charge and discharge current with respect to its nominal capacity). Karimi [5] particularly analyzed the performance of four main types of thermal management systems (TMS): free convection, forced convection, liquid cooling, and phase-change-material cooling. Panchal et al. [6,7] developed a numerical model to simulate a mini-channel cold plate and found that increased discharge rates and increased operating temperatures resulted in increased temperatures at cold plates, as experimentally measured. Meanwhile, many experiments were carried out on TMS to validate simulation results, such as serial and parallel air cooling [8], integrated liquid TMS [9], and expanded graphite based composite phase change materials [10]. These studies have produced many findings on the highest temperature control of battery packs.

In theoretical and experimental studies on thermal problems, researchers gradually discovered that temperature uniformity can also greatly influence battery performance as well as maximum temperature. That is because temperature variations cause electrochemical reactions to proceed at different C-rates in different regions of the cell, which thereby lead to incomplete energy utilization, and inefficient management of battery life. As a result, an outstanding TMS for EV should not only maintain the battery pack to work below maximum temperature limits, but should also maintain the battery temperature as uniform as possible. The temperature uniformity can be affected by the C-rate [11], cooling strategy [12], battery module arrangement [13], and so on. With the wide application of liquid cooling systems in modern EVs, coolant mass maldistribution in flowing channels will play a key role on temperature uniformity.

For liquid cooling, the coolant is used to absorb approximately $80-95 \%$ of the heat from a battery pack so that the performance of TMS strongly depends on coolant flowing characteristics. In order to maximally elevate its heat dissipation capacity, the cooling plate used in the system is usually manufactured with different internal flowing channels, where the coolant flows through and takes heat away from the battery pack. Regardless of flowing parameters and status, mass maldistribution in flowing channels will become an important force on temperature uniformity and system performance, as the maldistribution phenomenon can greatly induce an uneven liquid convection in the channels and consequently lead to a non-uniform heat transfer in the plate surface. However, for the problem of thermal uniformity caused by mass maldistribution in cooling plates used in EV batteries, there are still few papers focusing on it.

The significance of mass maldistribution on temperature uniformity can be shown in a micro-channel heat sink used in electric devices and other systems. Jin et al. [14] presented a multi-pass serpentine flow-field that could maximize under-rib convection in a given cell area and was expected to enhance under-rib convection and transport, thereby improving the performance and temperature uniformity of polymer electrolyte membrane fuel cells. Chein et al. [15] conducted a detailed numerical study on the effect of five different inlet/outlet configurations on flow distribution through comparison of temperature contours. Gui et al. [16] developed different parallel channels using a manifold with baffles and found the design with one to six bends could improve heat transfer and temperature uniformity significantly, but temperature non-uniformity was not improved by using more than four bends. Lu et al. [17] investigated the comprehensive performance of pressure drop and heat transfer based on rectangular parallel mini-channels with three different section surface areas and found that large ratios of height to width manifested a better comprehensive performance. Zhao et al. [18] employed numerical simulation to study the uniformity of velocity and temperature fields in parallel channel heat sinks and found the channels with derangement presented better performance when considering pressure drop and mean temperature of heat surfaces. Manoj et al. [19] carried out extensive experiments to study the parameters affecting pressure drop and temperature distribution across parallel channels, such as channel hydraulic diameter, flow configurations ( $U, Z, I$ type), and chip power, and found the configuration of inlet and outlet was important for heat performance. Javier et al. [20] analyzed the temperature distribution inside a Lytron CP20 microchannel cold plate under constant heat flux. The pressure drop across the first 
microchannel was very low due to the resistance to the flow caused mainly by the impact of the fluid to the wall of the outlet tube. Conversely, the pressure drop across the last channel was high because, due to the wall effect, the fluid coming from the previous channels pushed the fluid from the last one to the exit. Trevizoli et al. [21] carried out an experimental evaluation of the combined effect of void volume and inlet flow maldistribution to the thermal performance of active magnetic regenerators and found that the negative impact of inlet flow maldistribution on the regenerator effectiveness was more significant than that of void volume.

According to literature above, few have researched the effect of mass maldistribution on temperature uniformity of cooling plates, although many have researched micro-channels; however, their results cannot be applied directly to battery cooling as they are working at a much smaller scale dimension. The mass maldistribution can be induced by the variations of the amount of flowing mass, inlet and outlet arrangement, coolant flowing status (laminar or turbulent), and flowing channel configuration, which is considered to be the most important factor according to the studies of micro-channel and other systems. Therefore, the objective of this paper is to apply numerical analyses on different flowing channels in order to improve thermal uniformity (in terms of mass uniformity). The effect of channel configuration on mass maldistribution and pressure drop is compared, and serpentine channel is selected for further optimization by orthogonal experiment and range analysis methods due to its comprehensive performance. The study aims to reveal design principles about how channel configuration acts on mass maldistribution, and to demonstrate that significant performance gains can be realized with optimization techniques that can be utilized in battery cooling plates.

\section{Model Development and Simulation Method}

\subsection{Physical Model Establishment}

The cooling plate was of the same dimensions as the battery cell, and heat was transferred into the coolant through heat conduction and convection in the plate. Normally, there are three types of channel configurations used in cooling plates: cavity, parallel, and serpentine. The cavity type does not have flowing channels but rather an empty space in the plate. The parallel case is manufactured with many straight internal parallel paths. A serpentine flow-field is designed by forcing the coolant to flow through a single, long, meandering path that travels over the entire active area. Their configurations are demonstrated in Figure 1 and their dimensions are shown in Table 1.

The intervals of flowing channel and plate edges were all of $5 \mathrm{~mm}$ in width and length, but only $1 \mathrm{~mm}$ in thickness, for the sake of maximizing flow section area. Here the channel width was kept at $16 \mathrm{~mm}$ in parallel and serpentine channels to avoid the influence induced by different channel widths. For the same reason, only one inlet and one outlet were set in the same positions of the models. The 3-D models of the cooling plates were built in SolidWorks and then imported into ANSYS Workbench for simulation.

Since the objective of this paper was to design an optimized cooling plate channel structure and to study the effect of different structures on the pressure drop and mass maldistribution, the working conditions were simplified so that there was no heat applied on the plate. The other working conditions are also shown in Table 1. At the beginning, two cavities with outlets in different locations were modeled for reference, and then a basic parallel channel and serpentine channel were also studied for comparison with the reference cavity. 


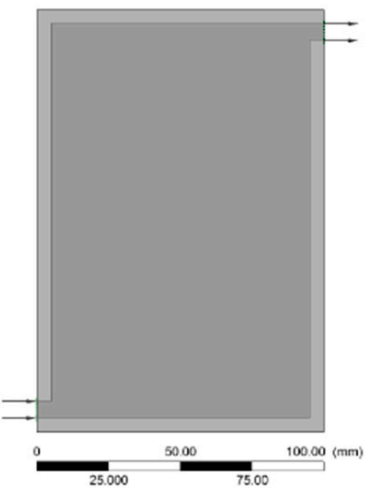

(a): cavity 1

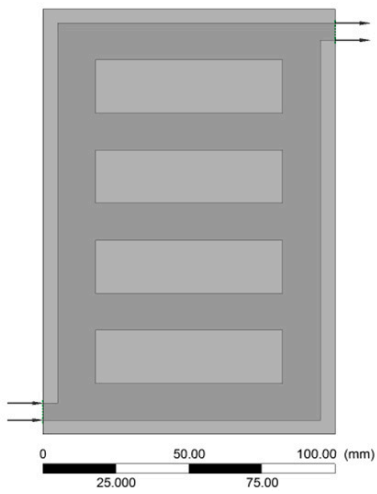

(d): parallel 1

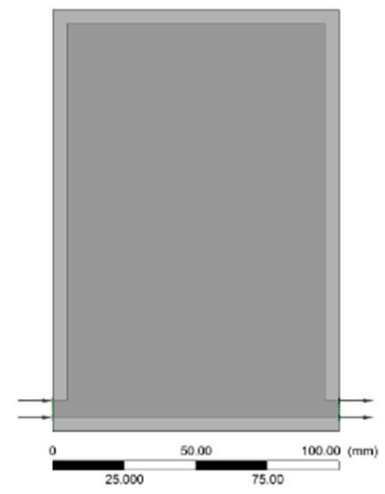

(b): cavity 2

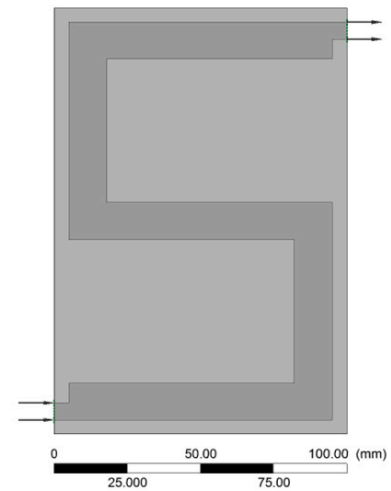

(e): serpentine 1

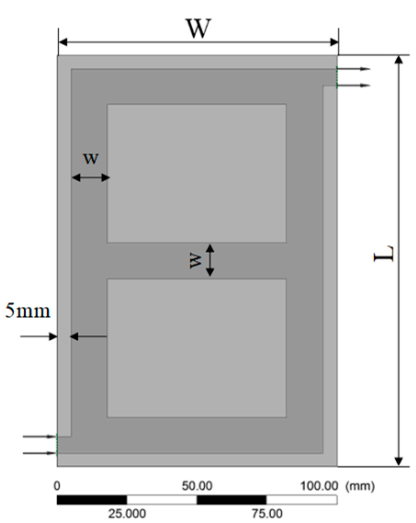

(c): parallel 1

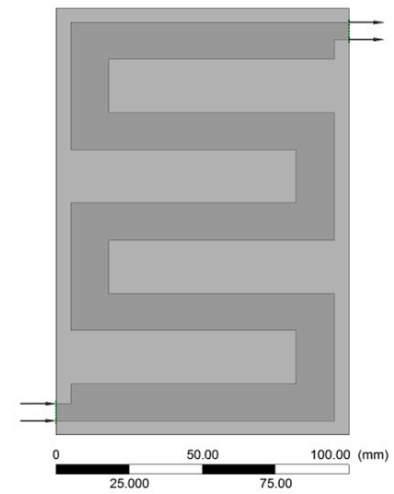

(f): serpentine 2

Figure 1. Schematic of CFD analysis models.

Table 1. Cooling plate analysis parameters and boundary conditions.

\begin{tabular}{cc}
\hline Material Properties & Value \\
\hline Dimensions & \\
Plate width $(\mathrm{W}$ in $\mathrm{mm})$ & 102 \\
Plate length $(\mathrm{L}$ in $\mathrm{mm})$ & 150 \\
Plate thickness $(\mathrm{mm})$ & 10 \\
Channel thickness $(\mathrm{mm})$ & 8 \\
Channel width $(\mathrm{w} \mathrm{in} \mathrm{mm})$ & 16 \\
Coolant fluid & Water \\
Coolant viscosity at $360 \mathrm{~K}(\mathrm{~Pa} \cdot \mathrm{s})$ & 0.0008623 \\
Coolant conductivity $\left(\mathrm{W} \cdot \mathrm{m}^{-1} \cdot \mathrm{K}^{-1}\right)$ & 0.612 \\
Coolant specific heat at $360 \mathrm{~K}\left(\mathrm{~J} \cdot \mathrm{kg}^{-1} \cdot \mathrm{K}^{-1}\right)$ & 4177 \\
Coolant density $\left(\mathrm{kg} \cdot \mathrm{m}^{-3}\right)$ & 996.5 \\
Plate material & Aluminum \\
Plate conductivity $\left(\mathrm{W} \cdot \mathrm{m}^{-1} \cdot \mathrm{K}^{-1}\right)$ & 202 \\
Plate specific heat $\left(\mathrm{J} \cdot \mathrm{kg}{ }^{-1} \cdot \mathrm{K}^{-1}\right)$ & 871 \\
Plate density $\left(\mathrm{kg} \cdot \mathrm{m}^{-3}\right)$ & 2719 \\
Boundary conditions & \\
Coolant inlet mass flow $\left(\mathrm{kg} \cdot \mathrm{s}^{-1}\right)$ & 0.1664 \\
Coolant inlet temperature $(\mathrm{K})$ & 360 \\
Coolant outlet pressure $(\mathrm{Pa})$ & 0 \\
Atmosphere temperature $(\mathrm{K})$ & 298 \\
\hline
\end{tabular}

\subsection{Evaluation Criterions}

For the pressure difference of cooling plates, the coolant pressure drop through channel $\Delta p$ is defined as follow: 


$$
\Delta p=p_{\text {in }}-p_{\text {out }}
$$

where: $p$ is coolant pressure, and subscript in and out indicate inlet and outlet of the plate, respectively.

The mass uniformity of the cooling plate is determined by mass distribution of flowing channels. Here, flowing mass uniformity coefficient $\varphi_{m}$ (mass standard deviation) is defined to reflect mass maldistribution:

$$
\varphi_{m}=\sqrt{\sum_{i=1}^{n}\left(m_{c}^{i}-m_{c}\right)^{2} / n}
$$

where $m_{c}{ }^{i}$ is averaged flowing mass of the $i$ th channel, and $m_{c}$ is averaged flowing mass of $n$ channels. The larger the value of $\varphi_{m}$, the more uneven the mass distribution in the channels is. If the value of $\varphi_{m}$ is equal to zero, it reveals that the flowing masses in each channel are all the same and mass maldistribution is eliminated. Therefore, a small value of $\varphi_{m}$ is the objective of this paper.

\subsection{CFD Analyses and Boundary Settings}

The mesh generation should balance simulation reliability against the computer calculation process. For the cooling plate and flowing water domain, structural hexahedral mesh was adopted since the model configuration was regular, as shown in Figure 1. After mesh generation using Ansys ICEM, the tool "mesh quality" in Ansys Workbench was used to check whether the mesh quality was good enough, and it was found that the values of all designs were near to 1 ( 1 means the best and 0 means the worst in Ansys Workbench). Then grid independence was studied. Case 2 in Section 3.2 was used as an example, and its results are shown in Figure 2. With the growth of grid number, the pressure drop of the inlet and outlet in the cooling plate was changing. Until the number of grids increased to 0.126 million, the curves of supervised pressure drop became smooth and steady. In overall consideration of hardware equipment, calculating time, and simulation error the total number of grids was set to be about 0.126 million in simulations that were conducted. The quantity and quality of mesh met the calculation requirements well and the construction method could be applied to the other models.

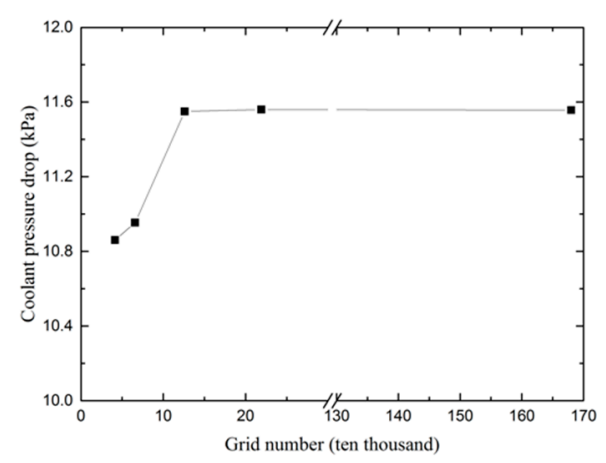

Figure 2. Grid independence of Case 2 in Section 3.2.

The FLUENT CFD solver was used to solve the governing equations for the conservation of mass, momentum, and energy for a Newtonian incompressible fluid. This study only considered the steady state condition, and the relevant equations are summarized as:

$$
\begin{gathered}
\frac{\partial u_{i}}{\partial x_{i}}=0 \\
\rho \frac{\partial\left(u_{i} u_{j}\right)}{\partial x_{i}}+\frac{\partial p}{\partial x_{i}}=\frac{\partial}{\partial x_{i}}\left(\mu \frac{\partial u_{j}}{\partial x_{i}}\right) \\
\rho \frac{\partial\left(u_{i} c_{p} T\right)}{\partial x_{i}}=\frac{\partial}{\partial x_{i}}\left(\lambda \frac{\partial T}{\partial x_{i}}\right)
\end{gathered}
$$


where $u$ and $x$ represent the velocity and direction vectors in Cartesian space; $\rho$ is the density; $p$ is the pressure; $\mu$ is the fluid viscosity; $c_{p}$ is the specific heat capacity; $T$ is the temperature; and $\lambda$ is the thermal conductivity.

Due to different channel widths in different designs, the Re number will be different, and is calculated by:

$$
R e=\frac{\rho u d_{h}}{\mu}
$$

where $d_{h}$ is equivalent hydraulic diameter and is equal to $4 A / P$ in the rectangular channel. Here $A$ is the cross section area of the channel, and $P$ is the wet perimeter of the channel. According to this formula, the Re number of Figure $1 \mathrm{a}$ as well as Figure $1 \mathrm{~b}$ was 2.443, and the others in Figure 1 were equal to 16.08. Hence, the simulation adopted a laminar flow model.

The coolant temperature of the inlet was fixed at $360 \mathrm{~K}$ and its mass volume flow was $0.1664 \mathrm{~kg} \cdot \mathrm{s}^{-1}$. The top surface was set to be free convection with a coefficient of $10 \mathrm{~W} / \mathrm{m}^{2} \cdot \mathrm{K}$ [22] and the surfaces of the solid and fluid were specified to be the interface. An adiabatic surface was applied to the other surfaces of the model. Aluminum and water were applied to the plate and coolant, respectively. At the outlet plane, the reference pressure (atmosphere pressure) was used here. For the coupling of the continuity and momentum equations, the solver used the Segregated/Implicit type, and adopted the SIMPLE algorithm to solve the coupled analyses of speed and pressure. This type of discrete equation adopts a second order upwind scheme. Convergence in all cases was declared only when both strict criteria were satisfied: (a) reduction in all residuals of five orders of magnitude at least; and (b) no observable change in surface temperature prediction for additional tens of iterations.

\section{Results and Discussion}

\subsection{Comparison of the Primary Channels}

Figure 3 shows the comparison of mass distributions for the six models in Figure 1. In Figure 3a,b, it can be observed that there was a large area of dead flow in the cavity of the cooling plates, which led to a large mass maldistribution, flow resistance to coolant, and increased pump power required for the coolant flowing through the plate. Therefore, for an empty plate, its pressure drop would be augmented due to no flowing channel. It could also validate the importance of designing a suitable flowing channel in a cooling plate. The good flowing channel should be designed to avoid dead flow and flow eddy in order to decrease pressure drop.

Note that although the dead flow zones were greatly reduced by the parallel and serpentine channels, there were still some dead flow zones existing especially at the corners of flowing channels. For parallel channels, regardless of channel number, most of the coolant flowed into one main channel and about 10-20 percentage flowed through the other channels; thus is can be derived that a parallel channel can lead to a large mass maldistribution and is bad for temperature uniformity.

Serpentine flow-field designs have been proposed to solve the maldistribution problem inherent to parallel flow-fields as it is only one flowing channel and there is no mass uniformity problem. However, the accompanying problem is that its flow speed and pressure drop are both very high. In order to increase heat transfer effect, the dissipation surface should be enlarged. One of the methods is to widen the channel but that will increase flow dead zones. Another method is to lengthen the tube path in the same plate. However, that will consequently increase the number of corners, resulting in a large local head loss and frictional pressure loss. Therefore, it needs further optimization to balance the mass uniformity and pressure loss. 

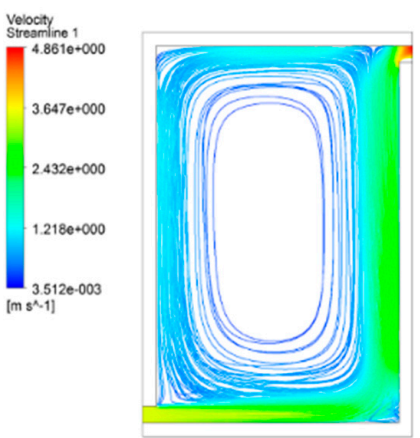

(a): cavity 1

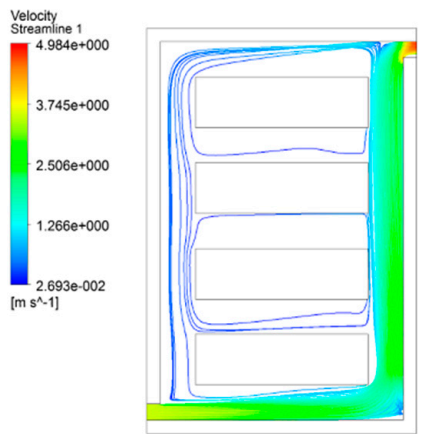

(d): parallel 1
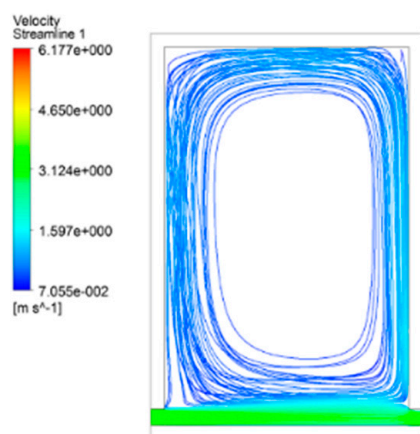

(b): cavity 2
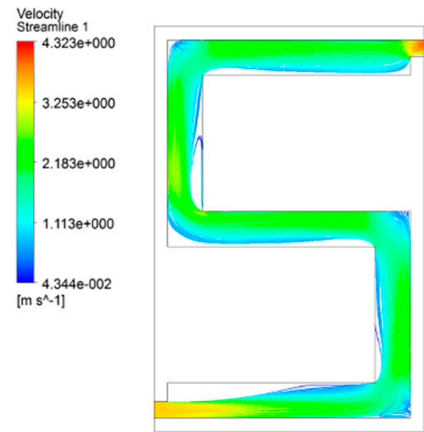

(e): serpentine 1

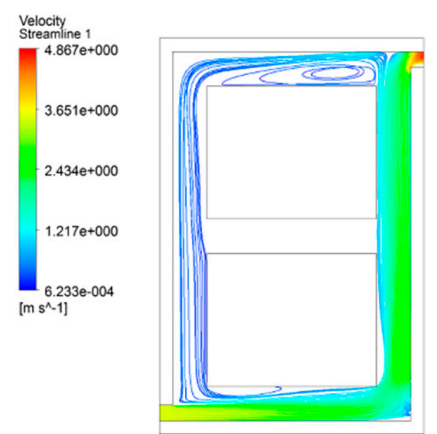

(c): parallel 1

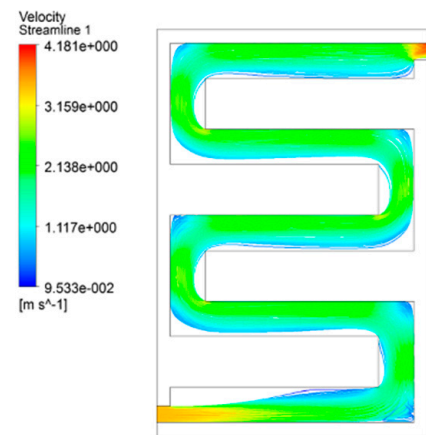

(f): serpentine 2

Figure 3. The flowing distribution of six models.

\subsection{Optimization of Serpentine Channel}

In order to enhance heat dissipation power, there must be some sacrifices in mass uniformity and pressure loss. The referred serpentine channel was the one to increase its channel width as large as possible and here in the present dimension its width was $45 \mathrm{~mm}$ as shown on the left of Figure 4 . For the optimization, some flow splitter plates were set along with the serpentine channel. The width of each splitter plate was $2 \mathrm{~mm}$. Then a splitter plate was used to branch the coolant into two flows and three plates were used for four flows, which can be seen in the right of Figure 4 . The dimensions of the different optimized strategies are shown in Table 2.

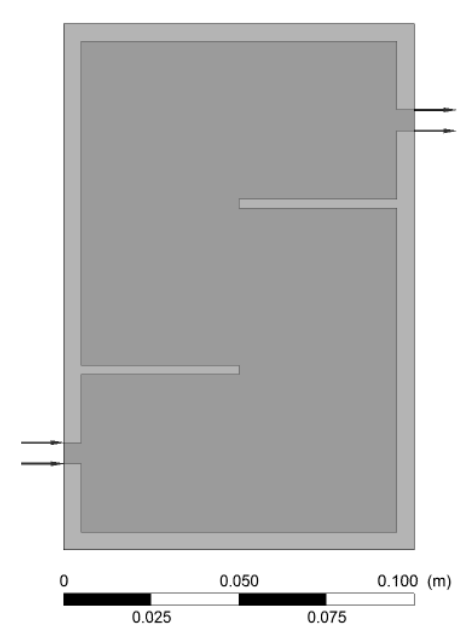

(a)

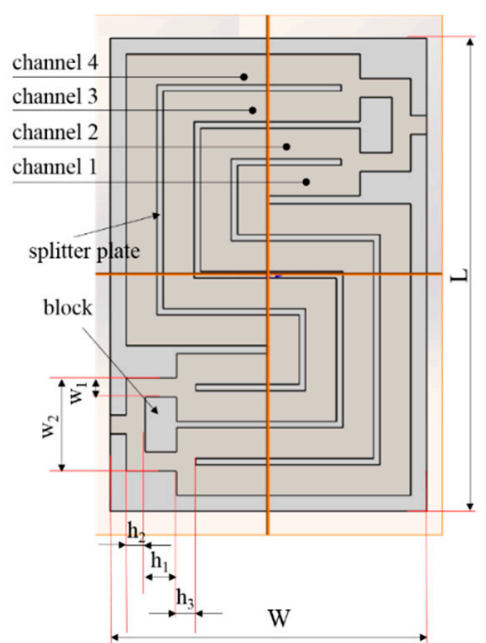

(b)

Figure 4. Middle section of computational domain for serpentine optimization. The left one is a referred serpentine channel of Case 1 with the largest channel width. The right one is a schematic of a flowing channel with splitter plates. 
Table 2. Value of the design variables in the six cases.

\begin{tabular}{cccccccc}
\hline Case & $\mathbf{w}_{\mathbf{1}}$ & $\mathbf{w}_{\mathbf{2}}$ & $\mathbf{h}_{\mathbf{1}}$ & $\mathbf{h}_{\mathbf{2}}$ & $\mathbf{h}_{\mathbf{3}}$ & $\mathbf{R e}$ & Remark \\
\hline 1 & 45 & - & - & - & - & 7.28 & without splitter plate \\
2 & 22.5 & - & - & 6 & - & 12.65 & one splitter plate \\
3 & 6 & 29.5 & - & 6 & - & 27.57 & three splitter plates \\
4 & 6 & 29.5 & 2 & 6 & 6 & 27.57 & three splitter plates \\
5 & 6 & 29.5 & 10 & 6 & 6 & 27.57 & three splitter plates \\
6 & 6 & 29.5 & 15 & 6 & 6 & 27.57 & three splitter plates \\
\hline
\end{tabular}

The flow detail and mass uniformity can be clearly observed in Figures 5 and 6 . Without any splitter plate, as seen in Figure 5a, coolant flowed mostly like the cavity plate type, as the channel width was as large as possible to increase the heat transfer surface. However, due to dead flow zones (the areas colored by white), its pressure drop was larger than those of Cases 2 and 3. Figure $5 \mathrm{~b}$ shows the flow process of Case 2 with one splitter plate. Compared with Case 1, its pressure drop decreased because most of coolant flow was restrained in the two channels so that the areas of dead flow zones and flow resistance were reduced. Furthermore, Case 2 showed better mass flow uniformity than Case 3, which was divided into four channels by three splitter plates. In Case 3, most coolant flowed into the two middle channels due to flow interference, as they directly connected to the inlet orifice without any flow turn, so that mass maldistribution was enlarged in this case. Conversely, however, its pressure dropped continuously because of the continuous decrease of the dead flow zone.
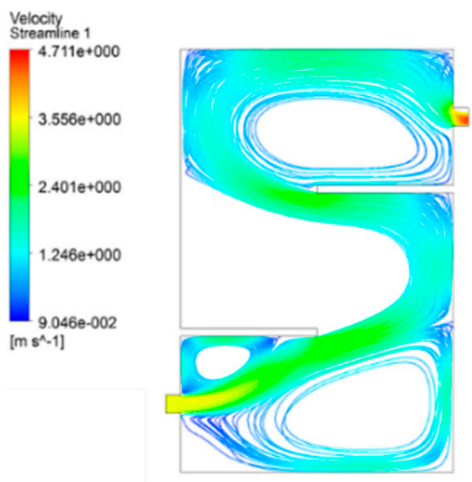

(a): Case 1
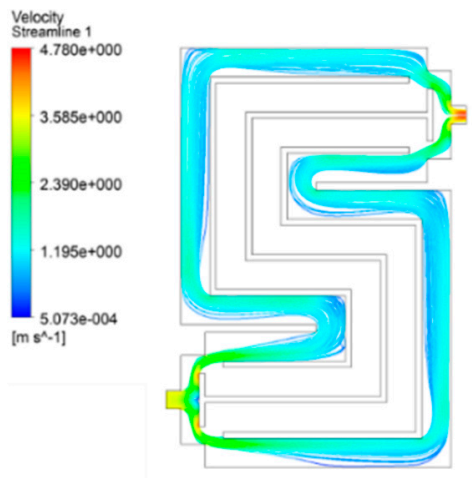

(d): Case 4

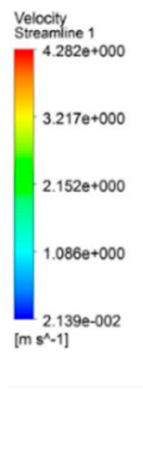

(b): Case 2

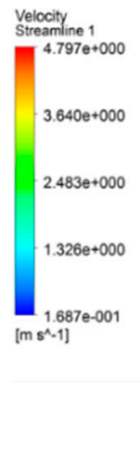

(e): Case 5
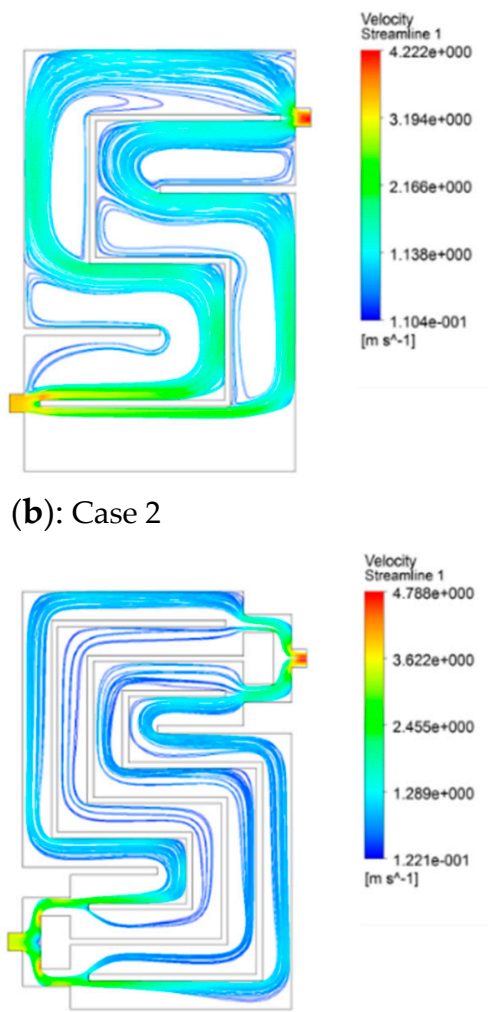

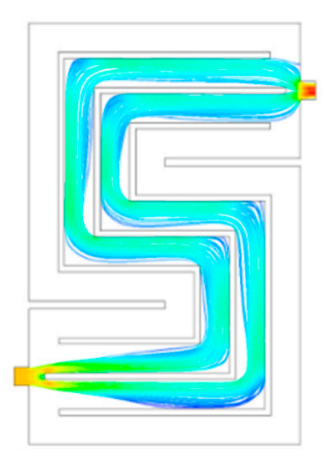

(c): Case 3

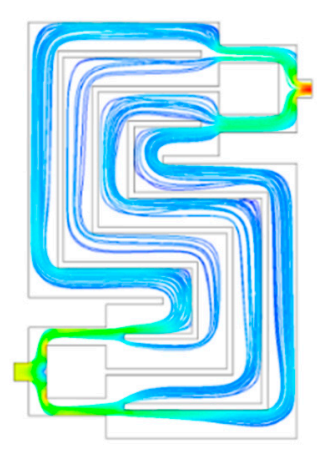

(f): Case 6

Figure 5. Flow characteristics of cooling plates of six models.

In order to improve mass maldistribution phenomena, a block was set in the inlet location. The block actively divided the coolant flowing into the different channels and mostly reduced the effect of flow interference. However, the structure of the block significantly influenced flow characteristics and heat transfer performance. Once the block was unsuitable, its effect could be against the improvement of mass uniformity and heat transfer capacity. Like Case 4, mass maldistribution 
did not improve but its pressure loss was greatly enlarged by local loss induced by the wall effect of the block. The large pressure loss also happened in Cases 5 and 6 . However, due to the promotion of block structure, mass maldistribution was greatly improved. All the pressure drops and mass percentages in each channel of the different cases are shown in Figure 6.

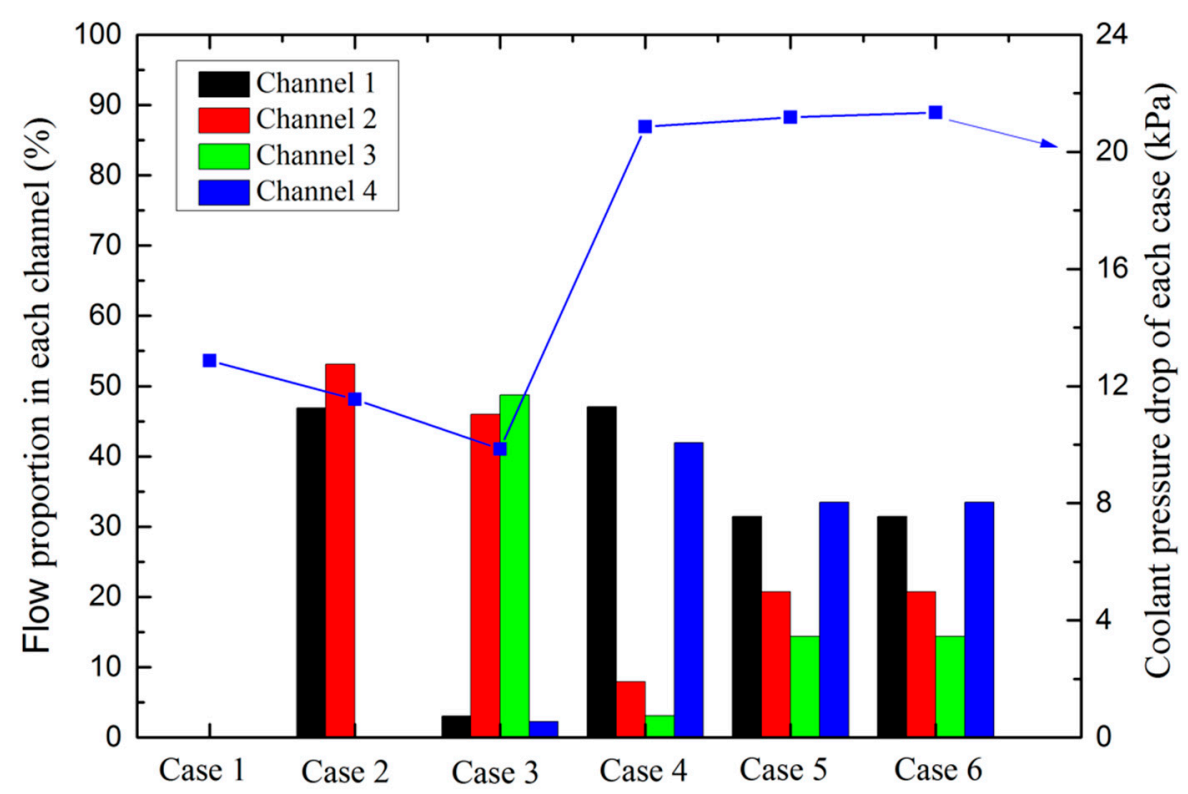

Figure 6. A comparison of six models in mass maldistribution and pressure drop.

Among the six cases, Cases 2 and 5 showed better comprehensive performance when taking mass uniformity and pressure drop into consideration. However, when the attention was paid to heat transfer as shown in Figure 7, the temperature in the bottom surface of the cooling plate with channel configuration of Case 5 was lower than that of Case 2. Here, in order to compare the temperature distributions of Cases 2 and 5, a heat flux of $50 \mathrm{~kW} / \mathrm{m}^{2}$ was applied on the bottom surface of the cooling plate, which was different from the above simulations without heat flux in Figures 3 and 5. The other boundary conditions were the same. Therefore, for an overall comparison of heat transfer and flow characteristic, Case 5 was selected for further optimization, as reported in Section 3.3.

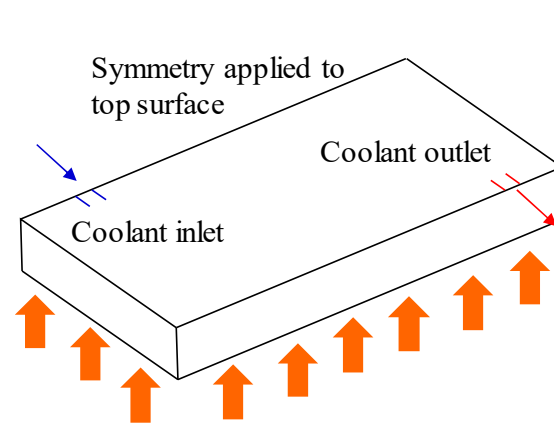

Heat flux applied to bottom surface

(a): Schematic of model with heat flux

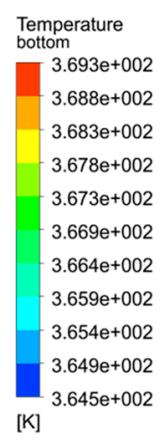

(b): Case 2

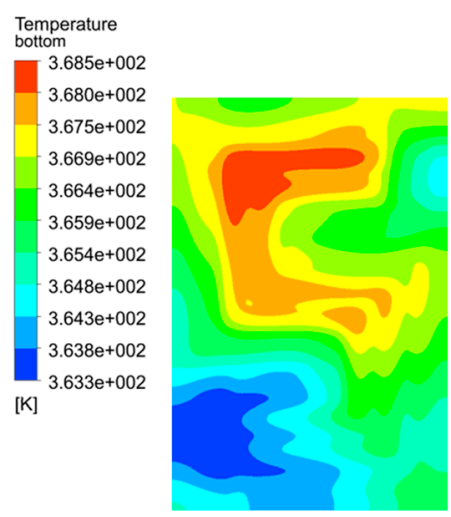

(c): Case 5

Figure 7. Temperature distributions of Case 2 and Case 5 . Here a heat flux of $50 \mathrm{~kW} / \mathrm{m}^{2}$ was applied on the bottom surface of cooling plate.

\subsection{Orthogonal Experiment and Range Analysis}

In Section 3.2, it was proved that a block structure can greatly affect the mass uniformity of the cooling plate, and hence an orthogonal experiment and range analysis were conducted based on Case 5 
to study the sensibility of structure parameters on flow mass uniformity and pressure drop. Here four parameters were chosen in the optimization: $w_{1}, h_{1}, h_{2}$, and $h_{3}$, as shown in Figure 4 . Each parameter had three levels and nine simulations were carried out, as shown in Table 3.

Table 3. Results of orthogonal experiment.

\begin{tabular}{ccccccc}
\hline Case & $\mathbf{A}\left(w_{\mathbf{1}}\right)(\mathbf{m m})$ & $\mathbf{B}\left(\boldsymbol{h}_{\mathbf{1}}\right)(\mathbf{m m})$ & $\mathbf{C}\left(\boldsymbol{h}_{\mathbf{2}}\right)(\mathbf{m m})$ & $\mathbf{D}\left(h_{\mathbf{3}}\right)(\mathbf{m m})$ & $\begin{array}{c}\text { Mass Uniformity } \\
\text { Coefficient } \varphi_{\boldsymbol{m}}\end{array}$ & $\begin{array}{c}\text { Pressure Drop } \\
\boldsymbol{\Delta} \boldsymbol{p} / \mathbf{k P a}\end{array}$ \\
\hline 1 & 6 & 10 & 6 & 6 & 0.131 & 25.473 \\
2 & 6 & 14 & 8 & 8 & 0.104 & 20.651 \\
3 & 6 & 18 & 10 & 10 & 0.108 & 18.151 \\
4 & 8 & 10 & 8 & 10 & 0.180 & 18.866 \\
5 & 8 & 14 & 10 & 6 & 0.153 & 17.048 \\
6 & 8 & 18 & 6 & 8 & 0.156 & 16.758 \\
7 & 10 & 10 & 10 & 8 & 0.149 & 14.778 \\
8 & 10 & 14 & 6 & 10 & 0.176 & 20.048 \\
9 & 10 & 18 & 8 & 6 & 0.162 & 16.309 \\
\hline
\end{tabular}

Considering the first evaluation criterion of mass uniformity coefficient, the calculation results are shown in Table 4. It is obvious that the most significant factor affecting mass maldistribution was channel width. The range value of channel width was about three to four times larger than the other three factors. The remaining parameters behaved less effectively to mass uniformity, except for the situation where $h_{1}$ decreased to a very small value when compared to $h_{2}$ and $h_{3}$. This can be seen in Figure 5, where $h_{1}$ was $2 \mathrm{~mm}$ and its mass maldistribution was more severe than Cases 5 and 6 , whose $h_{1}$ was not so small for the contrasting distances. Therefore, it can be confirmed that at constant volumetric flow, the most significant factor affecting mass flow and heat transfer was channel width, which was also validated by Jarrett, A. et al. [23]. In this simulation, the best structure for a minimum mass maldistribution was with $w_{1}$ of $6 \mathrm{~mm}, h_{1}$ of $18 \mathrm{~mm}, h_{2}$ of $10 \mathrm{~mm}$, and $h_{3}$ of $8 \mathrm{~mm}$.

Table 4. Results of range analysis on mass uniformity coefficient.

\begin{tabular}{cccccc}
\hline \multicolumn{7}{c}{ Mass Uniformity Coefficient } & Remarks \\
\hline A & B & C & D & \\
K1 & 0.343 & 0.460 & 0.463 & 0.446 & K is sum of mass uniformity coefficient: \\
K2 & 0.489 & 0.433 & 0.446 & 0.409 & $\mathrm{~K}=\mathrm{X}_{1}+\mathrm{X}_{2}+\mathrm{X}_{3}$ (X stands for A, B, C, D) \\
K3 & 0.487 & 0.426 & 0.410 & 0.464 & $\mathrm{~K}=\mathrm{K} / 3$ \\
k1 & 0.114 & 0.153 & 0.154 & 0.149 & $\mathrm{R}=\max \left(\mathrm{k}_{\mathrm{x}}\right)-\min \left(\mathrm{k}_{\mathrm{x}}\right)$ \\
k2 & 0.163 & 0.144 & 0.149 & 0.136 & \\
k3 & 0.162 & 0.142 & 0.137 & 0.155 & \\
R & 0.049 & 0.011 & 0.017 & 0.019 & \\
\hline Key factor & \multicolumn{7}{c}{$\mathrm{A}>\mathrm{D}>\mathrm{C}>\mathrm{B}$} & & $\mathrm{D}$ \\
\hline Better level & A1 & B3 & C3 & D2 \\
\hline
\end{tabular}

Considering the second evaluation criterion of pressure drop in Table 5, it showed the consumption of pump power needed for the coolant flowing through the channel. The channel width still played a key role in pressure drop, but the distance of $h_{2}$ showed the same importance as channel width, as their range values were almost the same. The long distance of $h_{2}$ led to a more moderate strike to the block when the coolant flowed into the channel, especially in a high speed. Here, the best structure for a minimum pressure drop was with a $w_{1}$ of $10 \mathrm{~mm}, h_{1}$ of $14 \mathrm{~mm}, h_{2}$ of $10 \mathrm{~mm}$, and $h_{3}$ of $8 \mathrm{~mm}$. As such, a small pressure drop required a wide channel and long distance of $h_{2}$ whereas for mass distribution it required a narrow channel and long distance of $h_{2}$. Since the distance of $h_{2}$ showed little effect on mass flow uniformity but much effect on pressure drop, the optimization 
of the channel for a balance of the two evaluation criterions was a narrow channel but a long distance of $h_{2}$ to gain a better comprehensive performance of the cooling plate.

Table 5. Results of range analysis on pressure drop.

\begin{tabular}{cccccc}
\hline \multicolumn{5}{c}{ Pressure drop } & Remarks \\
\hline K1 & A & B & C & D & \\
K2 & 52.275 & 59.117 & 62.279 & 58.830 & K is sum of mass uniformity coefficient: \\
K3 & 51.135 & 51.747 & 55.826 & 52.187 & K $\mathrm{X}_{1}+\mathrm{X}_{2}+\mathrm{X}_{3}(\mathrm{X}$ stands for A, B, C, D) \\
k1 & 21.425 & 19.706 & 20.760 & 19.610 & $\mathrm{~K}=\mathrm{K} / 3$ \\
k2 & 17.557 & 19.249 & 18.609 & 17.396 & $\mathrm{R}=\max \left(\mathrm{k}_{\mathrm{x}}\right)-\min \left(\mathrm{k}_{\mathrm{x}}\right)$ \\
k3 & 17.045 & 17.073 & 16.659 & 19.022 & \\
R & 4.380 & 2.633 & 4.101 & 2.214 & \\
\hline Key factor & \multicolumn{7}{c}{ A $>$ C $>$ D > B } \\
\hline Better level & A3 & B2 & C3 & D2 \\
\hline
\end{tabular}

\subsection{Limitations and Further Work}

The first limitation of this work is that there was no experiment to validate the value accuracy of mass maldistribution and pressure drop. However, as the objective of this paper focused on the effect of channel configuration on mass maldistribution and the same numerical method was proved to be reliable by experiments with a maximum difference of $10 \%$ due to our previous work in Liao, Y. [24], its value accuracy is considered to be an acceptable difference with experiment. Additionally, it is certain that the study of this work can be an instructive optimization for further cooling plate design in EVs. Another problem is that orthogonal experiments were carried out only with four, but not all parameters that can affect flow characteristics. More work is needed to study whether there are some key parameters missing. Furthermore, boundary conditions were also simplified in order to focus on the optimization method and configuration design. However, a cooling plate will experience a wide range of conditions during electric vehicle operation and it should be studied whether the design is still optimal for the practical EVs.

Further work can be carried out on the experimental test to prove value accuracy of the simulation and improve the numerical models from experimental feedback. Future work can include a full study on the effect of all the parameters in channel configuration on mass maldistribution using an optimized algorithm programmed in Matlab.

\section{Conclusions}

This paper presents a cooling plate with different internal flowing channels applied in thermal management systems for electric vehicle battery packs. Serpentine flow-field design shows great advantages in avoiding mass maldistribution over cavity and parallel channels, so that it is chosen for the next optimization by using splitter plates to reduce its pressure drop. Six serpentine flowing channels with different splitter plates and block structures were analyzed in numerical simulation. Based on the comparison in terms of mass uniformity, pressure drop, and heat transfer performance Case 5 of serpentine channel was further optimized by an orthogonal experiment and range analysis method. It was found that channel width was the most significant factor affecting mass maldistribution and pressure drop and it was suggested that a narrow channel but long distance of $h_{2}$ in a flowing channel was preferred to gain better comprehensive performance of the cooling plate. The research has revealed the design principles of uniform mass and temperature distribution for a cooling plate, which can hopefully promote the improvement of thermal management systems in electric vehicle batteries.

Author Contributions: The authors contributed equally to this work. 
Funding: The presented work was supported by the Natural Science Foundation of Fujian Province of China (Grant No. 2018D0018), and CAS Key Laboratory of Cryogenics, TIPC (Grant No. CRYO201708).

Conflicts of Interest: The authors declare no conflict of interest.

\section{Nomenclature}

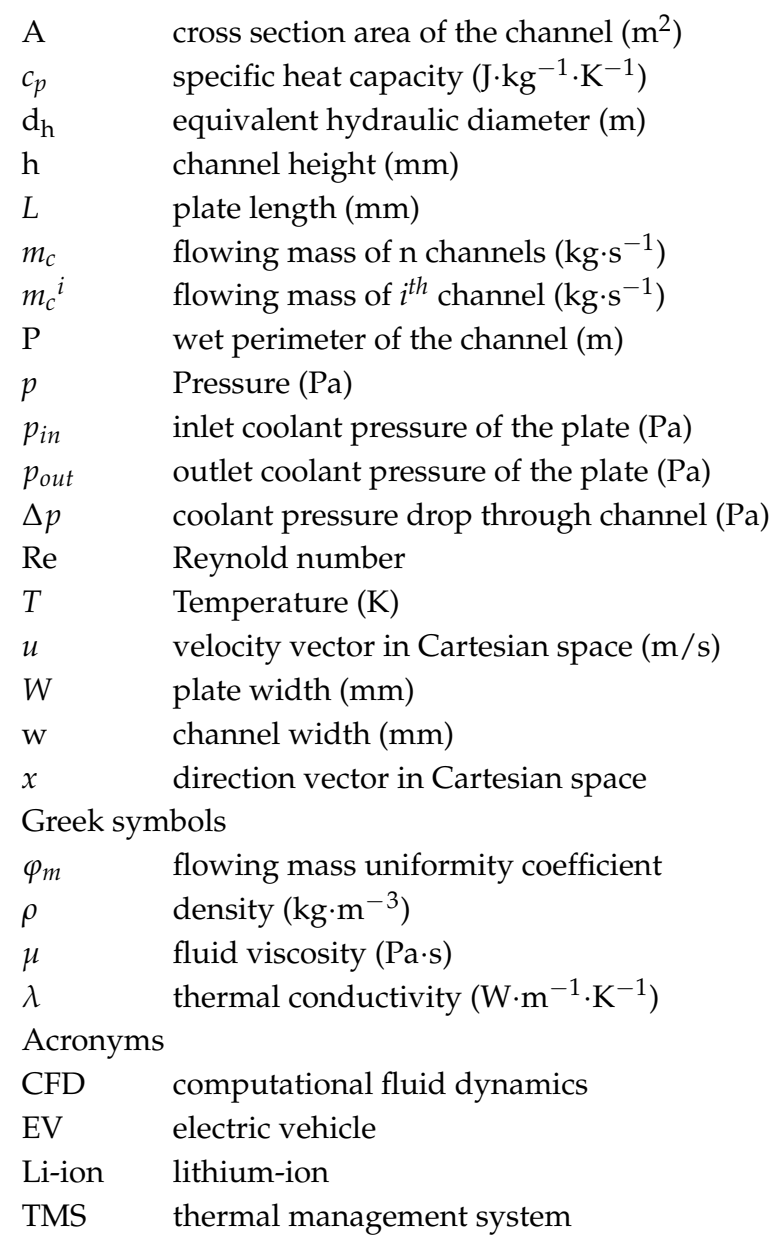

\section{References}

1. Campanari, S.; Manzolini, G.; de la Iglesia, F.G. Energy analysis of electric vehicles using batteries or fuel cells through well-to-wheel driving cycle simulations. J. Power Sources 2009, 186, 464-477. [CrossRef]

2. Pesaran, A.A.; Market, T.; Tataria, H. Battery Requirements for Plug-In Hybrid Electric Vehicles-Analysis and Rationale; Office of Scientific \& Technical Information Technical Reports; Press of Anaheim: Anaheim, CA, USA, 2009; pp. 2-5.

3. Mills, A.; Al-Hallaj, S. Simulation of passive thermal management system for lithium-ion battery packs. J. Power Sources 2005, 141, 307-315. [CrossRef]

4. Chen, Y.; Evans, J.W. Thermal analysis of lithium polymer electrolyte batteries by a two dimensional model-Thermal behavior and design optimization. Electrochim. Acta 1994, 39, 517-526. [CrossRef]

5. Karimi, G.; Li, X. Thermal management of lithium-ion batteries for electric vehicles. Int. J. Energy Res. 2013, 37, 13-24. [CrossRef]

6. Panchal, S.; Khasow, R.; Dincer, I.; Agelin-Chaab, M.; Fraser, R.; Fowler, M. Thermal design and simulation of mini-channel cold plate for water cooled large sized prismatic Lithium-ion battery. Appl. Therm. Eng. 2017, 122, 80-90. [CrossRef]

7. Panchal, S.; Khasow, R.; Dincer, I.; Agelin-Chaab, M.; Fraser, R.; Fowler, M. Numerical modeling and experimental investigation of a prismatic battery subjected to water cooling. Numer. Heat Transf. Part A Appl. 2017, 71, 626-637. [CrossRef] 
8. Zhu, X. Study in Wind Cooling System for RAV-4 EV Packs. Master's Dissertation, Nanjing University of Aeronautics and Astronautics, Nanjing, China, 2007. (In Chinese)

9. Zhang, T. Investigation on Heat Transfer Enhancement of Packing Battery with Liquid Flow and Vehicle Integrated Thermal Management. Ph.D. Dissertation, Jilin University, Jilin, China, 2016. (In Chinese)

10. Ling, Z. Performance Investigation of the Power Battery Thermal Management System Using Expanded Graphite Based Composite Phase Change Materials. Ph.D. Dissertation, South China University of Technology, Guangzhou, China, 2016. (In Chinese)

11. Zhao, C.; Cao, W.; Dong, T.; Jiang, F. Thermal modeling of cylindrical lithium-ion battery module with micro-channel liquid cooling. Ciesc J. 2017, 68, 3232-3241. (In Chinese)

12. Xu, X.; Zhao, Y. Research on battery module thermal characteristics based on double inlet and outlet flow path liquid-cooled system. Chin. Mech. Eng. 2013, 24, 313-316. (In Chinese)

13. Yuan, H.; Wang, L.; Wang, L. Battery thermal management system with liquid cooling and heating in electric vehicles. J. Automot. Saf. Energy 2012, 3, 371-380. (In Chinese)

14. Nam, J.H.; Lee, K.J.; Sohn, S.; Kim, C.J. Multi-pass serpentine flow-fields to enhance under-rib convection in polymer electrolyte membrane fuel cells: Design and geometrical characterization. J. Power Sources 2009, 188, 14-23. [CrossRef]

15. Chein, R.; Chen, J. Numerical study of the inlet/outlet arrangement effect on microchannel heat sink performance. Int. J. Therm. Sci. 2009, 48, 1627-1638. [CrossRef]

16. Lu, G.; Duan, Y.; Wang, X. Effects of manifold designs on flow and thermal Performances of microchannel heat sink. J. Basic Sci. Eng. 2013, 21, 345-354. (In Chinese)

17. Lu, J.; Han, Y. Experimental test for comprehensive performance of heat sink with parallel mini-channel. Cryog. Supercond. 2014, 42, 48-52. (In Chinese)

18. Zhao, W.; Lv, Y.; Lu, J.; Han, Y.; Gao, Y. Research on the uniformity of flow rate and heat transfer characteristics of heat sink with parallel mini-channels. J. Anhui Univ. Technol. (Nat. Sci.) 2016, 33, 343-348. (In Chinese)

19. Manoj, S.V.; Arvind, P.; Sarit, K.D. Effect of flow maldistribution on the thermal performance of parallel microchannel cooling systems. Int. J. Heat Mass Transf. 2014, 73, 424-428. [CrossRef]

20. Javier, A.N.; Hugh, T.; Markus, P.R.; Robert, J.W. Computational modeling of a microchannel cold plate: Pressure, velocity, and temperature profiles. Int. J. Heat Mass Transf. 2014, 78, 90-98.

21. Trevizoli, P.V.; Peixer, G.F.; Nakashima, A.T.; Capovilla, M.S.; Lozano, J.A.; Barbosa, J.R. Influence of inlet flow maldistribution and carryover losses on the performance of thermal regenerators. Appl. Therm. Eng. 2018, 133, 472-482. [CrossRef]

22. Yang, S.; Tao, W. Heat Transfer, 4th ed.; Higher Education Press: Beijing, China, 2010.

23. Jarrett, A.; Kim, Y. Design optimization of electric vehicle battery cooling plates for thermal performance. J. Power Sources. 2011, 196, 10359-10368. [CrossRef]

24. Liao, Y. Design and Performance Study of Surface Air-Oil Heat Exchanger; Xiamen University: Xiamen, China, 2018. (In Chinese)

(C) 2019 by the authors. Licensee MDPI, Basel, Switzerland. This article is an open access article distributed under the terms and conditions of the Creative Commons Attribution (CC BY) license (http:/ / creativecommons.org/licenses/by/4.0/). 